\title{
Arthroscopic assisted fixation of central depressed lateral tibial plateau fracture: case report
}

\author{
Vijay Shankar*, Shyam Sundar, David V. Rajan \\ Department of Sports Medicine, Ortho One Orthopaedic Speciality Centre, Coimbatore, Tamil Nadu, India
}

Received: 12 March 2020

Accepted: 09 April 2020

*Correspondence:

Dr. Vijay Shankar,

E-mail: vijayshankar230989@gmail.com

Copyright: ( $)$ the author(s), publisher and licensee Medip Academy. This is an open-access article distributed under the terms of the Creative Commons Attribution Non-Commercial License, which permits unrestricted non-commercial use, distribution, and reproduction in any medium, provided the original work is properly cited.

\begin{abstract}
Arthroscopic assisted fixation has become the gold standard for managing Schatzker III tibial plateau fractures. There are different techniques available to reduce and fix the central depression. We present one such case of a 41 years old female who had good outcome following arthroscopic assisted fixation using anterior cruciate ligament guide, dilators and calcium hydroxyapatite bone substitute.
\end{abstract}

Keywords: Schatzker III, Arthroscopy, Tibial plateau, Grafting

\section{INTRODUCTION}

Tibial plateau fractures account for $1.2 \%$ of all fractures and they commonly involve the lateral tibial condyle. This can be in the form of a split or central depression. The latter comes under Schatzker III/AO 41B2 classification of proximal tibial injuries. These classically occur after a low energy valgus mechanism.

Open approach for pure lateral condyle depression does not provide adequate visualization of the depressed fragment unless an osteotomy or arthrotomy is performed. Moreover, soft tissue dissection and arthrotomy significantly hinder postoperative recovery. The morbidity of open approach has favoured indirect reduction techniques and arthroscopic assisted reduction for this type of fracture..$^{1-4}$ We report one such case of pure depressed lateral condyle fracture which was reduced arthroscopically and fixed with percutaneous raft screws using medial metaphyseal bone window technique. ${ }^{4}$

\section{CASE REPORT}

A forty one year old female presented to our emergency department with pain and swelling over the right knee following fall from a two-wheeler one week back. She was unable to bear weight on the affected limb. Clinical examination revealed a stable knee with painful range of motion and distal neurovascular status was intact.

Plain radiographs and computerized tomographic (CT) scans revealed a pure depression lateral condyle tibia fracture (Figure 1). The outer lateral cortex was intact.

\section{Surgical technique}

Under spinal anaesthesia, patient is positioned supine on the operating table. A thigh tourniquet was placed along with a lateral thigh post and a foot post.

Examination under anaesthesia revealed a stable knee. Diagnostic arthroscopy was performed through standard anterolateral and anteromedial portals. Saline inflow was gravity assisted without any pressure pumps. Lateral condyle depression was visualized under the free edge of body of lateral meniscus (Figure 2).

After proper visualization of the depression, with the help of a ligamentoplasty aimer (arthrex ACL aimer), a single $\mathrm{K}$-wire was passed from medial surface of tibia towards the depressed fragment (Figure 3). $8 \mathrm{~mm}$ reamer was used over the K-wire to open the cortex and serial dilators were 
used to push cancellous bone of tunnel towards depressed fragment. This was confirmed visually with arthroscope through anterolateral portal (Figure 4).

Under fluoroscopy guidance, with the fracture held reduced by the dilator in the tibial tunnel, it was fixed with a single K-wire passed from lateral to medial direction in the subchondral bone, parallel to the joint line. Once the $\mathrm{K}$-wire hits the dilator, wire placement is confirmed. The dilator was then removed and $\mathrm{K}$-wire advanced. A $6.5 \mathrm{~mm}$ cannulated cancellous screw was placed over the K-wire and the anteromedial tunnel was packed with calcium hydroxyapatite ( $\mathrm{G}$ bone).

\section{Follow-up}

Patient was non-weight bearing on the affected limb for the first three weeks and gradual weight bearing was started thereafter. Range of motion was started after three weeks. At six months follow-up, patient has full range of motion and has returned back to her activities of daily living. Six months follow-up radiographs show union at fracture site without collapse (Figure 5B).

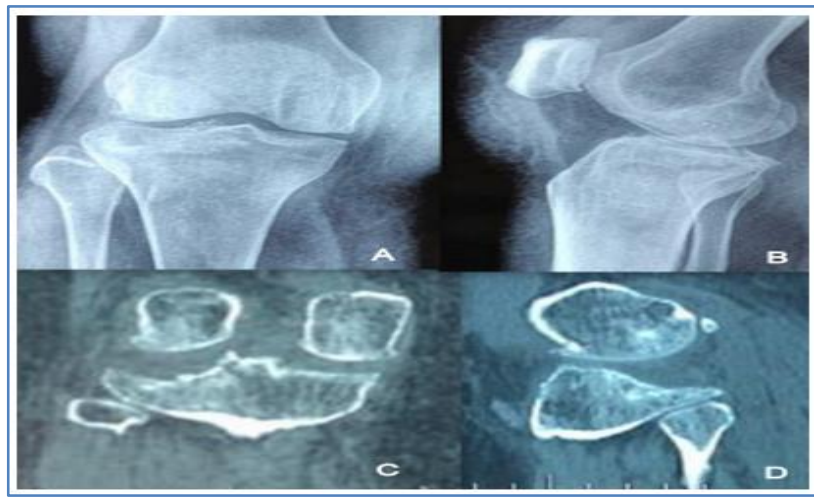

Figure 1: A) Plain radiographs AP, B) lateral views showing Schatzker III tibial plateau fracture, C) coronal and sagittal, D) CT cuts showing intact lateral cortex with central depression.

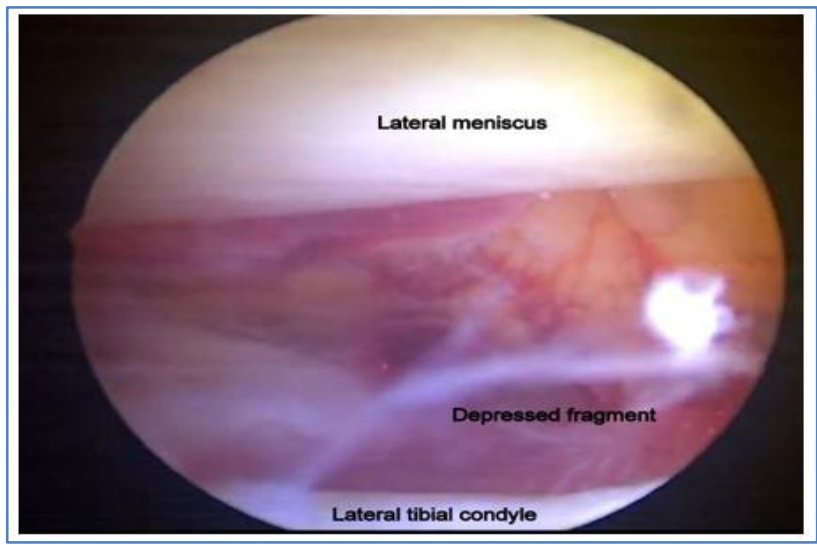

Figure 2: Arthroscopic view from anterolateral portal showing depressed fragment and floating lateral meniscus.

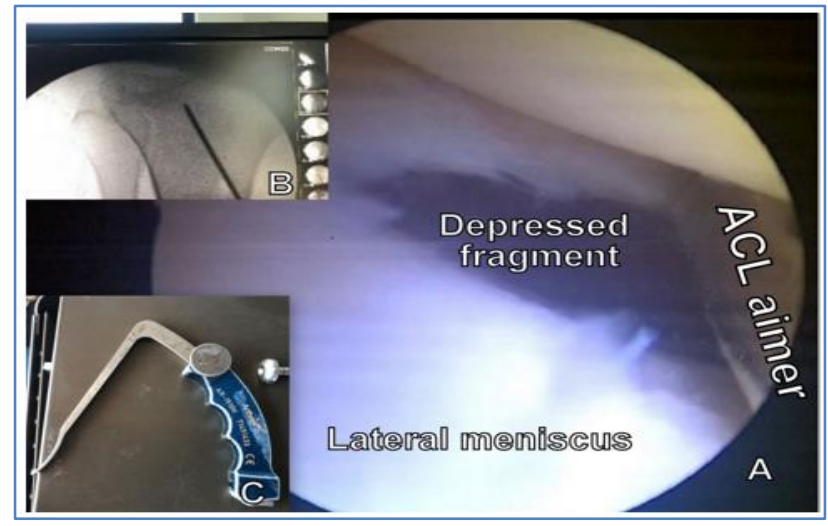

Figure 3: A) Arthroscopic view showing placement of anterior cruciate ligament aimer, B) corresponding fluoroscopic image of guide pin, C) anterior cruciate ligament aimer.

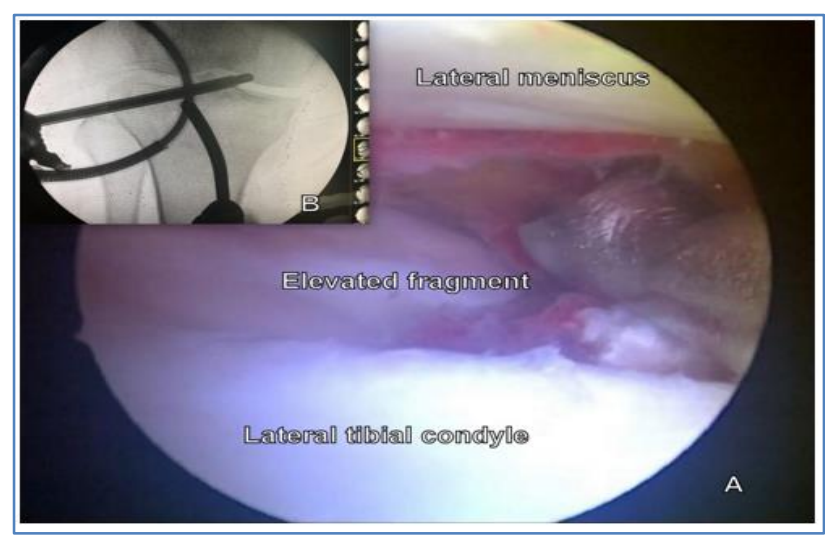

Figure 4: A) Arthroscopic image showing final elevation of depressed fragment, B) corresponding fluoroscopic image of dilator through anteromedial tunnel.

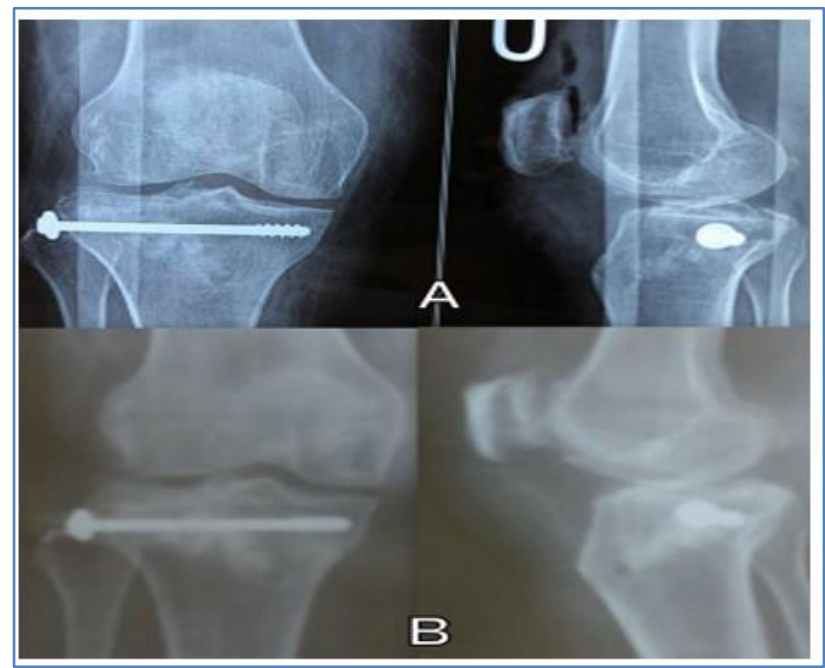

Figure 5: A) Plain AP and lateral radiographs showing immediate postop fixation, B) union at six months follow-up. 


\section{DISCUSSION}

Arthroscopic assisted fixation has become the norm in Schatzker I, II and III fractures of tibial plateau. This is especially true for the pure central depression injuries where it is difficult to view the depression, unless a submeniscal arthrotomy or lateral cortex osteotomy is done. Arthroscopic assisted fixation has the advantage of less fluoroscopy time, better restoration of articular surface, addressing concomitant meniscal/chondral injuries and faster rehabilitation. ${ }^{1-4}$

Chen et al performed a systematic review of 19 level III and level IV studies on arthroscopic assisted fixation in tibial condyle fractures. ${ }^{5}$ This review included 609 patients with a mean follow-up of 52.5 months. $90.9 \%$ of patients had excellent results with only 6 cases encountering complications. In another systematic review by Hong et al, involving 12 studies with 353 patients, 80\% had good Rasmussen scores suggesting the usefulness of arthroscopy in these fractures. ${ }^{6}$

The main drawback with arthroscopy is the risk of compartment syndrome with saline inflow. This can be alleviated by avoiding pressure pumps and establishing intermittent outflow. We utilized an ACL aimer to drill the tibial tunnel from medial surface of tibia to the depressed fragment. The use of ligamentoplasty aimers to create pinpoint tunnels to the desired location has been described. ${ }^{1-4,7}$ Establishing a longer tunnel from the medial side has the advantage of procuring more cancellous bone for elevating the depressed fragment.

After adequate elevation by dilators through the anteromedial tunnel, the next step was fixation of the fragment with raft screws passed parallel to the joint line. This screw was passed just below the subchondral bone under fluoroscopic guidance.

General consensus is to pack the tibial tunnel with graft. We opted for calcium hydroxyapatite to avoid additional morbidity associated with graft harvest and also due to its higher fatigue strength. ${ }^{8,9}$

This case report adds to the available literature that arthroscopic assisted medial metaphyseal bone window technique is very useful in managing pure depression type of lateral tibial condyle fractures.
Funding: No funding sources

Conflict of interest: None declared

Ethical approval: Not required

\section{REFERENCES}

1. Ozkut AT, Poyanli OS, Ercin E, Akan K, Esenkaya I. Arthroscopic technique for treatment of Schatzker type III tibia plateau fractures without fluoroscopy. Arthroscopy techniques. 2017;6(1):195-9.

2. Rossi R, Castoldi F, Blonna D, Marmotti A, Assom M. Arthroscopic treatment of lateral tibial plateau fractures: a simple technique. Arthroscopy: The J of Arthroscopic Rel Surg. 2006;22(6):678-1.

3. Hartigan DE, McCarthy MA, Krych AJ, Levy BA. Arthroscopic-assisted reduction and percutaneous fixation of tibial plateau fractures. Arthroscopy Techniques. 2015;4(1):51-5.

4. Lubowitz JH, Elson WS, Guttmann D. Part I: arthroscopic management of tibial plateau fractures. Arthroscopy: J Arthroscopic Rel Surg. 2004;20(10):1063-70.

5. Chen XZ, Liu CG, Chen Y, Wang LQ, Zhu QZ, Lin P. Arthroscopy-assisted surgery for tibial plateau fractures. Arthroscopy: J Arthroscopic Rel Surg. 2015;31(1):143-53.

6. Chen HW, Liu GD, Wu LJ. Clinical and radiological outcomes following arthroscopic-assisted management of tibial plateau fractures: a systematic review. Knee Surg, Sports Traumatol, Arthroscopy. 2015;23(12):3464-72.

7. Rossi R, Bonasia DE, Blonna D, Assom M, Castoldi F. Prospective follow-up of a simple arthroscopicassisted technique for lateral tibial plateau fractures: results at 5 years. Knee. 2008;15(5):378-83 .

8. Egol KA, Cantlon M, Fisher N, Broder K, Reisgo A. Percutaneous repair of a Schatzker III tibial plateau fracture assisted by arthroscopy. J Orthopaedic Trauma. 2017;31:12-3.

9. Donald ME, Chu T, Tufaga M, Marmor M, Singh R, Yetkinler D, et al. Tibial plateau fracture repairs augmented with calcium phosphate cement have higher in situ fatigue strength than those with autograft. J Orthopaedic Trauma. 2011;25(2):90-5.

Cite this article as: Shankar V, Sundar S, Rajan DV. Arthroscopic assisted fixation of central depressed lateral tibial plateau fracture: case report. Int J Res Orthop 2020;6:649-51. 